\title{
V protein, the virulence factor across the family Paramyxoviridae: a review
}

\author{
May Ling Tham ${ }^{\mathrm{a}}$, Khatijah Yusoffa, ${ }^{\mathrm{a}, \mathrm{b}}$, Sarah Othman ${ }^{\mathrm{c}}$, Suet Lin Chia ${ }^{\mathrm{a}, \mathrm{d}^{*}}$ \\ ${ }^{a}$ Department of Microbiology, Faculty of Biotechnology and Biomolecular Sciences, Universiti Putra Malaysia, 43400 UPM Serdang, Selangor, \\ Malaysia \\ ${ }^{b}$ Malaysia Genome Institute, National Institute of Biotechnology Malaysia, Jalan Bangi, 43000 Kajang, Selangor, Malaysia \\ 'Department of Cell and Molecular Biology, Faculty of Biotechnology and Biomolecular Sciences, Universiti Putra Malaysia, 43400 UPM \\ Serdang, Selangor, Malaysia \\ 'Institute of Bioscience, Universiti Putra Malaysia, 43400 UPM Serdang, Selangor, Malaysia
}

Received 15th February 2019 / Accepted 6th July 2019

\begin{abstract}
Paramyxoviridae is a family of viruses within the order Mononegavirales and comprises 14 genera; Metaavulavirus, Orthoavulavirus, Paraavulavirus, Synodonvirus, Ferlavirus, Aquaparamyxovirus, Henipavirus, Morbillivirus, Respirovirus, Jeilongvirus, Narmovirus, Salemvirus, Pararubulavirus and Orthorubulavirus. The members within this family are negative and single-stranded RNA viruses including human and animal pathogens such as measles virus $(\mathrm{MeV})$, Nipah virus $(\mathrm{NiV})$, mumps virus $(\mathrm{MuV})$, Sendai virus $(\mathrm{SeV})$ and Newcastle disease virus (NDV). The V protein is conserved within the family and plays an essential role in viral pathogenicity. Although $\mathrm{V}$ proteins of many paramyxoviruses are interferon-antagonists which counteract with the host's innate immunity, there are still differences in the mode of action of the $\mathrm{V}$ protein between different genera or species within the same genera. The strategies to circumvent the host interferon (IFN) pathway can be divided into three general mechanisms; degradation of signal transducers and activators of transcription (STAT) protein, inhibition of phosphorylation of the transcription factor and, inhibition of translocation of STAT proteins into the nucleus. As a result, inhibition of IFN signalling and production promotes viral replication in the host cells. This review highlights the mechanism of the paramyxoviral V protein in evading the host IFN system.
\end{abstract}

Keywords: Paramyxoviridae, Mononegavirales, P gene, V protein, interferon, virulence factor

\section{Members of the Paramyxoviridae}

The family of Paramyxoviridae belongs to the order Mononegavirales and consists of four subfamilies: Avulavirinae, Metaparamyxovirinae, Orthoparamyxovirinae, and Rubulavirinae (Adapted from Amarasinghe et al., 2019). A total of 14 genera with three unclassified species were formed as shown in Table 1 (Supplementary). Members of the Avulavirus have been reclassified into Metaavulavirus, Orthoavulavirus, and Paraavulavirus; members of the Rubulavirus have also been reclassified into Orthorubulavirus and Pararubulavirus. For the ease of discussion, the Avulavirus and Rubulavirus will be used to present members of their respective subfamily. The virions in the family of Paramyxoviridae are mainly spherical with a diameter of $150 \mathrm{~nm}$ to $300 \mathrm{~nm}$ but they can be filamentous and pleomorphic as well (Takimoto and Portner, 2004; Harrison et al., 2010). The genetic material of the viruses consists of single-stranded, negative-sense and non-

\footnotetext{
*Author for correspondence: Dr. Suet-Lin Chia, Department of Microbiology, Faculty of Biotechnology and Biomolecular Sciences, Universiti Putra Malaysia, 43400 Serdang, Selangor, Malaysia. Email suetlin@upm.edu.my.
} 
segmented RNA. Their natural hosts range from humans (such as the measles virus) to animals (such as the Newcastle disease virus) (Young et al., 2000; Ganar et al., 2014).

\subsection{Genomic content of Paramyxoviridae}

Although the members of the Paramyxoviridae are highly diverse, they share a common genome structure. The genome starts with a 3' leader sequence of approximately 50 nucleotides and ends with a 5' trailer region (Fearns and Plemper, 2017). Both the leader and trailer sequences are untranslated regions which are involved in viral replication and genome packaging ( $Y$ an and Samal, 2008). The paramyxoviruses contain six main genes which are nucleocapsid $(\mathrm{N})$, phosphoprotein $(\mathrm{P})$, matrix $(\mathrm{M})$, fusion $(\mathrm{F})$, attachment $(\mathrm{G} / \mathrm{H} / \mathrm{HN})$ and polymerase $(\mathrm{L})$ that encode for six structural proteins, respectively (Audsley and Moseley, 2013). The genes are flanked with conserved regions known as gene start, intergenic region and gene end (Fearns and Plemper, 2017). The arrangement of the genes in the genome is shown in Figure 1. Firstly, the gene that is closest to the $3^{\prime}$ end of the genome is the $\mathrm{N}$ gene that encodes the nucleocapsid protein (NP) which binds to the viral RNA and protects the genome from nuclease digestion (Choppin and Compans, 1975; Yusoff and Tan, 2001). The RNA genome follows the rule-of-six where one nucleocapsid protein will encapsidate six nucleotides to allow efficient replication by viral polymerase (Calain and Roux, 1993). The genomic RNA and NP forms a helical ribonucleoprotein (RNP) complex that is recognized by the viral RNA-dependent RNA polymerase, which is made up of $\mathrm{P}$ protein and $\mathrm{L}$ protein (Ganar et al., 2014; Cox and Plemper, 2017). The L protein exhibits the catalytic activities of polymerase whereas the $\mathrm{P}$ protein facilitates the binding of P-L complex to nucleocapsid (Dortmans et al., 2010; Fearns and Plemper, 2017). The matrix gene encodes for the highly hydrophobic and basic matrix $(\mathrm{M})$ protein (Chambers et al., 1986; Yusoff and Tan, 2001). M proteins are located between the nucleocapsid and the inner surface of the lipid envelope (Ganar et al., 2014). These proteins aid in virus assembly and virus budding through interaction with the host plasma membrane (Harrison et al., 2010; Ganar et al., 2014).

The genome of paramyxoviruses encodes for two transmembrane glycoproteins, the fusion (F) protein and the attachment protein. These proteins are encoded by different genes in different genera. For example, the attachment protein for Rubulavirus and Avulavirus is encoded by the haemagglutinin-neuraminidase $(\mathrm{HN})$ gene; Respirovirus and Morbillivirus have haemagglutinin $(\mathrm{H})$ gene for their attachment protein whereas glycoprotein $(\mathrm{G})$ protein is encoded by Henipavirus (Harrison et al., 2010). These surface glycoproteins present on the viral envelope as 'tiny spikes' projecting from the outermost layer of the virion (Yusoff and Tan, 2001; Ganar et al., 2014). The last gene to undergo transcription upon viral replication is the $\mathrm{L}$ gene that codes for the L protein (Yusoff et al., 1987; Ganar et al., 2014). Besides being part of the viral polymerase, the $\mathrm{L}$ protein also carries out post-transcriptional modification such as 5' capping, methylation, polyadenylation on the newly synthesised mRNA (Dortmans et al., 2010).

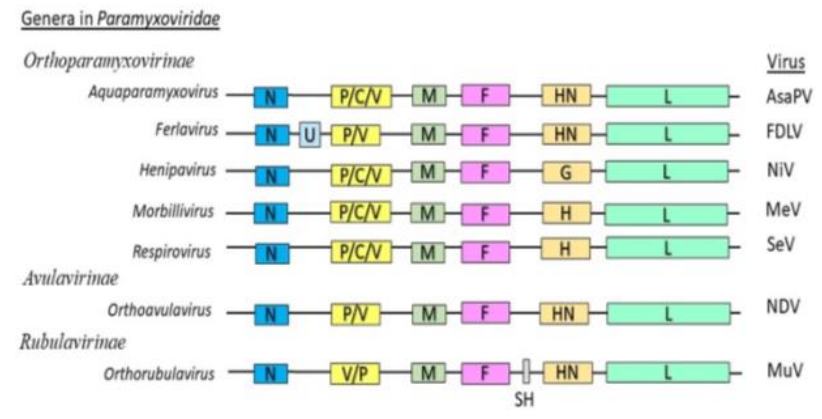

Figure 1. The 3'-5' genomic RNA of paramyxoviruses with boxes represent the open reading frame (ORF) of viral proteins. Multiple ORFs that present within a gene are indicated by a slash (/) (Modified from MacLachlan and Dubovi, 2017).

Depending on the genus, the $\mathrm{P}$ gene also encodes additional protein apart from the $\mathrm{P}$ protein (Ganar et al., 2014; Young et al., 2000). The $\mathrm{P}$ gene of Avulaviruses encodes for $\mathrm{V}$ and $\mathrm{W}$ proteins at the same time (Young et al., 2000; Mebatsion et al., 2001). Whilst the P mRNA is a constant transcript for the $\mathrm{P}$ gene in Avulavirus, Respirovirus, Henipavirus and Morbillivirus, the generation of the $\mathrm{V}$ and $\mathrm{W}$ mRNA requires 
addition of non-templated guanine $(\mathrm{G})$ residue(s) (+1 frameshift and +2 frameshift, respectively) (Steward et al., 1993; Young et al., 2000). The frequencies of production of the $\mathrm{P}, \mathrm{V}$, and $\mathrm{W}$ proteins that are derived from the $\mathrm{P}$ gene in Avulaviruses are estimated to be at $68 \%, 29 \%$, and $5 \%$ respectively (Mebatsion et al., 2001). On the other hand, the Respirovirus, Henipavirus, and Morbillivirus encode both the $\mathrm{V}$ and $\mathrm{C}$ proteins within the open reading frame of $\mathrm{P}$ gene (Young et al., 2000; Parks and Alexander-Miller, 2013). In Rubulavirus, the $\mathrm{V}$ protein is produced from the $\mathrm{P}$ gene. The $\mathrm{V}$ mRNA is an invariable product from the $\mathrm{P}$ gene. Apparently, the production of the $\mathrm{P}$ mRNA requires insertion of two non-templated guanine $(\mathrm{G})$ residues ( +2 frameshift) (Steward et al., 1993; De Leeuw and Peeters, 1999; Young et al., 2000). Rubulaviruses do not encode the C protein but they have a small hydrophobic $(\mathrm{SH})$ gene which is located between the $\mathrm{F}$ and $\mathrm{HN}$ genes (De Leeuw and Peeters, 1999).

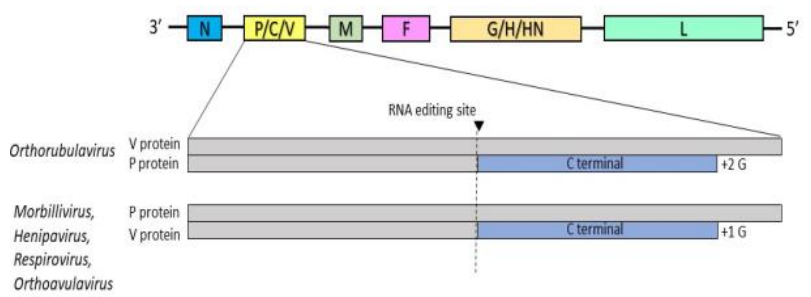

Figure 2. The coding strategies of paramyxoviruses to generate $\mathrm{P}$ and $\mathrm{V}$ protein. The $\mathrm{V}$ protein shared the identical $\mathrm{N}$-terminal protein sequences with $\mathrm{P}$ protein but different $\mathrm{C}$-terminal (highlighted in blue) due to addition of nontemplate guanine residue(s) at the RNA editing site. Production of $\mathrm{V}$ mRNA from $\mathrm{P}$ gene requires additional of one guanine residue $(+1 \mathrm{G})$ in Morbillivirus, Henipavirus, Respirovirus and Avulavirus whereas $\mathrm{V}$ mRNA is a constant transcript in Rubulavirus and $\mathrm{P}$ mRNA is generated through two guanines insertion $(+2 \mathrm{G})$.

These proteins ( $\mathrm{P}, \mathrm{V}$ and $\mathrm{W}$ proteins) from the $\mathrm{P}$ gene share the same amino $(\mathrm{N})$ terminal but different carboxyl $(\mathrm{C})$ ends in terms of the length and amino acid constituents (Figure 2) (Huang et al., 2003). The mechanism to generate mRNA that encodes for the $\mathrm{P}, \mathrm{V}$ and $\mathrm{W}$ proteins is known as RNA editing at the conserved editing site through addition of $G$ nucleotides in the open reading frame of P protein (Steward et al., 1993; Parks and
Miller, 2013). The V protein of NDV, parainfluenza virus 5 (PIV-5) and mumps virus are found to be a structural constituent incorporated into the virions but the $\mathrm{V}$ proteins of Sendai virus and measles virus are not incorporated into the virions (Curran et al., 1991; Paterson et al., 1995; Steward et al., 1995; Patterson et al., 2000). The $\mathrm{V}$ proteins function as an interferon-antagonist in paramyxoviruses and they are considered as accessory proteins of the $\mathrm{P}$ gene (Gotoh et al., 2001; Audsley and Moseley, 2013).

\section{Evading cellular anti-viral response}

\subsection{Interferon signalling overview}

Interferons (IFN) are the main cytokines or signalling molecules involve in the first line of host defence system also known as innate immunity against viral infections. The main function of IFN is to establish an antiviral state among uninfected cells through transcription of antiviral genes as well as induce apoptosis in infected cells to stop virus replication (Tanaka et al., 1998; Huang et al., 2003; Parks and AlexanderMiller, 2013). IFN can be classified into type one (IFN-I) and type two interferon (IFN-II). IFN-I consists of IFN- $\alpha$ and IFN- $\beta$ which are produced in cells upon viral infection (Tanaka et al., 1998). IFN-II comprises IFN- $\gamma$ and is confined to mitogen or cytokine activated lymphoid cells such as $\mathrm{T}$ helper cells, cytotoxic $\mathrm{T}$ cells and natural killer (NK) cells (Samuel, 2001; Tanaka et al., 1998). The response of IFN-I signalling pathway towards viral infection will be discussed in this review.

Figure 3 shows the regulation of IFN signalling in the cell. The cell surface receptor for IFN-I is made up of two subunits which are IFNAR-1 and IFNAR-2. Binding of IFN to their respective receptors will cause the latter to undergo heterodimerisation (Samuel, 2001). Stimulation of different types of IFN will lead to activation of different Janus family of tyrosine kinases (JAK) (Tanaka et al., 1998). For instance, IFNAR-1 subunit will interact with TYK2 whereas IFNAR-2 will interact with JAK1. After that, the underlying cytoplasmic signal transducers and activators of transcription (STAT) proteins are phosphorylated by JAK 
enzymes (Qiu et al., 2016). IFN-I stimulates the formation of heterotrimer IFN-stimulated gene factor 3 (ISGF-3) consisting of phosphorylated STAT1, STAT2, and interferon regulatory factor 9 (IRF-9), which is also known as p48 protein (Samuel, 2001). These structures are then translocated into the nucleus where they will bind to the cis-acting DNA elements, IFN-stimulated response element (ISRE), to further transcribe IFN inducible genes (Samuel, 2001; Qiu et al., 2016). Among the interferon-induced anti-viral proteins are double-stranded RNA activated protein kinase (PKR), 2', 5'-oligoadenylate synthetase (OAS), and the Mx proteins (Clemens, 1997; Floyd-Smith et al., 1981; Haller et al., 1998). Evasion of pro-apoptotic mechanism of host cell is required to allow successful viral replication and spreading of progenies in a cell (O'Brien, 1998; Roulston et al., 1999). Through evolution, many paramyxoviruses have established strategies to counteract the antiviral response induced by IFN. One of the accessory proteins, the $\mathrm{V}$ protein, that is a common IFN antagonist across Paramyxoviridae and its mechanism interacting with the host IFN pathway will be discussed further.

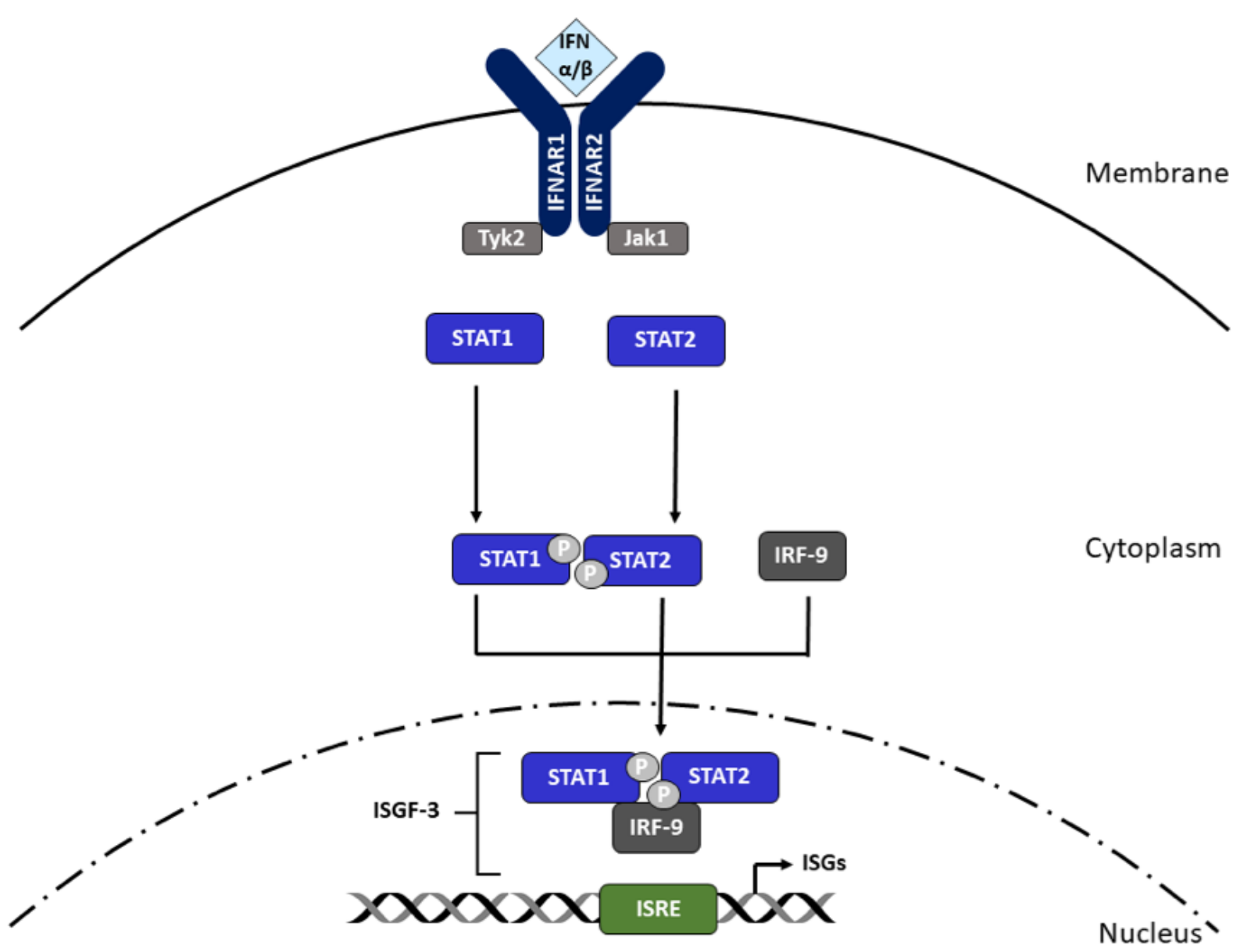

Figure 3. Regulation of IFN signalling through Janus kinase (JAK) - signal transducer and activator of transcription (STAT) pathway. Binding of IFN to type I interferon receptor leads to the activation of TYK2 and JAK1 kinase. STAT proteins are then phosphorylated and dimerised, followed by forming a complex called IFN-stimulated gene factor 3 (ISGF-3) with interferon regulatory factor 9 (IRF-9). The ISGF-3 translocates into the nucleus and binds to the IFN-stimulated response element (ISRE) to initiate the transcription of targeted genes. 


\subsection{Biological role of $\mathrm{V}$ protein of paramyxoviruses}

\subsubsection{Mumps virus (MuV), parainfluenza virus 5 (PIV-5) and human parainfluenza virus type 2 (HPIV-2) from genus Orthorubulavirus}

$\mathrm{MuV}$ targets STAT1 and STAT2 to prevent activation of the IFN signalling in cells. It was found that cells persistently infected with $\mathrm{MuV}$ experienced a loss of STAT1 protein despite being treated with IFN and proteasome inhibitors (Yokosawa et al., 1998). Kubota et al. (2002) demonstrated that the $\mathrm{V}$ protein is able to bind to receptor-activated $\mathrm{C}$ kinase (RACK1), which is an adaptor to facilitate the binding of STAT1 protein to the IFN receptor. It was also shown that STAT1 is able to interact with $\mathrm{MuV}$ instead of RACK1. As a result, the interaction between STAT1 and IFN receptor is inhibited. This may be the reason why IFN signalling can be inhibited prior to STAT1 protein degradation (Kubota et al., 2005). Moreover, the $\mathrm{C}$ terminal of $\mathrm{MuV} \mathrm{V}$ protein is capable of inhibiting the tyrosine phosphorylation of both the STAT1 and STAT2 instead of only targeting STAT1 degradation (Kubota et al., 2005). Besides, a tryptophan-rich motif in the cysteine rich $\mathrm{C}$ terminus of the $\mathrm{MuV}$ $\mathrm{V}$ protein is also responsible for ubiquitination and degradation of STAT1 (Nishio et al., 2002; Yokosawa et al., 2002). The complete abolishment of the $\mathrm{V}$ protein in $\mathrm{MuV}$ led to high induction level of a proinflammatory cytokine, interleukin-6 (IL-6) attracting monocytes to the site of infection quickly and attenuating the $\mathrm{MuV}$ (Xu et al., 2012).

The $\mathrm{V}$ protein of PIV-5, formerly known as simian virus (SV5), was found to block the IFN signalling by proteasomal degradation of STAT1 protein in human, murine and canine cells (Didcock et al., 1999; Young et al., 2001; Chatziandreou et al., 2004). According to Precious et al. (2005), the $\mathrm{V}$ protein links UV-damaged DNA-binding protein (DDB1), STAT1, STAT2, and Cullin $4 \mathrm{a}$ to form a ubiquitin ligase complex, which is involved in the ubiquitination of the STAT1 protein. In the absence of STAT2 protein in the ubiquitin ligase complex, the STAT1 protein will not be ubiquitinated for degradation. This interferon antagonistic activity is contributed by the $\mathrm{C}$-terminus of $\mathrm{V}$ protein because the IFN$\beta$ induction is higher in cells infected with recombinant PIV-5 (C terminal deficient) as compared to the infection with wild type PIV-5 (Poole et al., 2002). As a result of STAT1 protein degradation, formation of ISGF-3 and gamma activation factor (GAF), a homodimer of phosphorylated of STAT1, is inhibited causing the breakdown of signals to establish an antiviral state to suppress virus replication (Didcock et al., 1999). In other words, PIV-5 and $\mathrm{MuV}$ are capable of inhibiting both type I and type II IFN (Young et al., 2000). Unlike $\mathrm{MuV}$, recombinant PIV-5 without $\mathrm{V}$ protein expression could not be recovered (He at al., 2002). This observation suggested that $\mathrm{V}$ protein might play a role in viral replication in PIV-5 as compare to $\mathrm{MuV}$ (Xu et al., 2012).

Andrejeva et al. (2004) showed that the V protein of PIV-5 as well as the other paramyxoviruses such as $\mathrm{HPIV}-2, \mathrm{SeV}, \mathrm{MuV}$ and $\mathrm{HeV}$, interacts with melanoma differentiationassociated gene 5 (MDA-5), a RNA helicase with a caspase recruitment domain (CARD) at its amino end that is inducible by the host IFN. The interaction between the helicase and $\mathrm{C}$ terminal of $\mathrm{V}$ protein represses the activation of both $\mathrm{NF}-x \mathrm{~B}$ and IRF-3 which is the transcription factor that binds to IFN- $\beta$ promoter upon detection of polyinosinic polycytidylic acid (poly I:C), the synthetic analogue for dsRNA (He et al., 2002; Poole et al., 2002; Childs et al., 2007). Although the viral genome from Paramyxoviridae is ssRNA, dsRNA appears to be the replicative intermediate in infected cells (Jacobs and Langland, 1996). Hence, the $\mathrm{V}$ protein of paramyxoviruses can limit the intracellular dsRNA signalling that triggers the IFN transcription (Poole et al., 2002; Childs et al., 2007).

On the other hand, HPIV-2 from Rubulavirus blocks the IFN signalling by proteolytic degradation of STAT2 protein instead of STAT1 protein (Young et al., 2000; Parisien et al., 2001). Since STAT2 protein is a component of ISGF-3 that will later bind to ISRE in the promoter of IFN I inducible genes, type I IFN will be blocked due to the loss of STAT2 protein (Parisien et al., 2001).

In short, although the IFN signalling is initiated upon viral infections, time is taken to degrade the STAT proteins. For example, the STAT1 protein in PIV-5 infected cells degrade completely at least $12 \mathrm{~h}$ post-infection (Didcock et 
al., 1999). Moreover, near complete degradation of the STAT2 protein in HPIV-2 infected CV1, a monkey kidney cell line occurs at $9 \mathrm{~h}$ postinfection (Parisien et al., 2001). In CV1 and Vero cells infected by $\mathrm{MuV}$, STAT1 degradation is more time consuming since more than $50 \%$ of the STAT1 protein is still present after $24 \mathrm{~h}$ postinfection as compared to uninfected cells (Kubota et al., 2005). Hence it was proposed that Rubulaviruses might have other mechanisms than protein degradation to antagonise the host IFN pathway.

\subsubsection{Newcastle disease virus (NDV) from genus Orthoavulavirus}

The IFN system of avian cell during NDV infection is ineffective due to the presence of the $\mathrm{V}$ protein which degrades the STAT1 protein (Huang et al., 2003). Qiu et al. (2016) showed that the $\mathrm{V}$ protein selectively targets the phosphorylated STAT1 protein for ubiquitinmediated proteolytic degradation. Hence the total level of STAT1 protein is reduced due to the decrease of phosphorylated STAT1 protein. The $\mathrm{C}$ terminal of the $\mathrm{V}$ protein is responsible for IFN antagonistic activity similar to that of the $\mathrm{C}$ terminal of $\mathrm{V}$ protein in $\mathrm{MuV}$ and HPIV-2 (Huang et al., 2003).

The $\mathrm{V}$ protein of NDV can also prevent apoptosis in avian cells and thus enhance the virus replication in host cells with a complete IFN system (Mebatsion et al., 2001; Park et al., 2003a; Huang et al., 2003; Chu et al., 2018). This property of the $\mathrm{V}$ protein contributes to the specific host range of NDV (Park et al., 2003a). Later, Chu et al. (2018) found that the $\mathrm{V}$ protein targets the host Calcyclin-Binding Protein and Siah-1 Interacting Protein (CacyBP/SIP) to inhibit cell apoptosis in chicken embryo fibroblasts (DF-1) cells through Caspase 3 pathway. Topolskawo et al. (2016) showed that the function of the CacyBP/SIP is associated to dephosphorylation of protein, ubiquitination, cytoskeletal dynamics, and some of the cellular processes such as gene expression, cell proliferation, differentiation, and tumourigenesis. As a result, virus replication is promoted in NDV infected cells.

Besides, recombinant NDV lacking $\mathrm{V}$ protein expression is found to be less pathogenic than the parental wild type NDV based on pathogenicity studies such as mean death time (MDT), intracerebral pathogenicity index (ICPI) and intravenous pathogenicity index (IVPI) (Huang et al., 2003). According to Park et al. (2003a), when the NS1 gene from influenza A virus is inserted into a recombinant NDV with carboxyl end deficient $\mathrm{V}$ protein, the virus replication in embryonated eggs and chicken embryo fibroblast is restored and is comparable to that of the wild type NDV. Hence it can be concluded that the influenza NS1 protein is having the same function as $\mathrm{V}$ protein of NDV where both of them act as interferon antagonist.

\subsubsection{Measles virus (MeV) from genus Morbillivirus}

The $\mathrm{V}$ protein of $\mathrm{MeV}$ was found to interrupt the translocation of both STAT1 and STAT2 proteins to the nucleus after IFN $\alpha$ treatment (Palosaari et al., 2003). In addition, the phosphorylation of STAT proteins is inhibited but they are not prone to degradation (Takeuchi et al., 2003). The $\mathrm{N}$ terminal of $\mathrm{V}$ protein interacts with STAT1 and JAK1 whereas zinc domain in C terminus of $\mathrm{V}$ protein facilitates the binding between the $\mathrm{V}$ protein itself and the STAT2 protein (Caignard et al., 2007; 2009). Therefore, the $\mathrm{V}$ protein of $\mathrm{MeV}$ interferes with IFN $\alpha, \beta$ and $\gamma$ signalling (Takeuchi et al., 2003; Caignard et al., 2009).

On the other hand, the $\mathrm{P}$ protein of $\mathrm{MeV}$ blocks the STAT1 phosphorylation and colocalises with STAT proteins in the cytoplasm. The $\mathrm{P}$ protein interacts with the linker domain and SH2 domain of STAT1 protein resulting in the inhibition of STAT1 phosphorylation by JAK1 (Devaux et al., 2013). Apparently, tyrosine 110 at the $\mathrm{N}$ terminal of $\mathrm{P}$ protein contributes to this cytoplasmic retention or sequestration of STAT1 protein in $\mathrm{MeV}$ (Devaux et al., 2007).

In addition, the IFN exhibits both autocrine and paracrine properties where its transcription in virus infected cells will produce a positive feedback loop in these cells as well as the uninfected neighbouring cells as shown in Figure 3 (Samuel, 2001; Perry et al., 2005). Plasmacytoid dendritic cell precursors (pDCs) is the primary type I IFN producer expressing high level of TLR7 and TLR9 but not TLR2, 3, 4, 5 and 8 within the endosome (Liu, 2005). The ligand for 
TLR7 is a single stranded viral RNA whereas the ligand for TLR9 is unmethylated CPG DNA motifs on viruses and bacteria (Hemmi et al., 2000; Diebold et al., 2004; Heil et al., 2004; Lund et al., 2004). Upon detection of RNA viruses, TLR7 and TLR9 utilise an adaptor molecule myeloid differentiation factor-88 (MyD88) to transmit downstream IFN signalling (Perry et al., 2005). MyD88 will form a complex with tumour necrosis factor receptor-associated factor-6 (TRAF6), IRF7, interleukin-1 receptor-associated kinase (IRAK-1) and IRAK-4 in the cytoplasm (Honda et al., 2004; Kawai et al., 2004; Hengel et al., 2005). In this complex, E3 ubiquitin ligase activity of TRAF6 activates IRF7 (Honda et al., 2004; Kawai et al., 2004). Besides IRAK, I $x$ B kinase $\alpha(\operatorname{IKK} \alpha)$ was also shown to phosphorylate IRF7 (Hoshino et al., 2006). When IRF7 is activated by phosphorylation, it homodimerises and translocates into the nucleus to bind to the promoter of IFN-I and induce their expression (Honda et al., 2004; Kawai et al., 2004; Pfaller and Conzelmann, 2008). However, Pfaller and Conzelmann (2008) found that the $\mathrm{C}$ terminus of $\mathrm{MeV} \mathrm{V}$ protein will bind to IKK $\alpha$ and IRF7 and result in inhibition of IFN induction through TLR7/9 and MyD88-mediated pathway. Thus, the $\mathrm{V}$ protein becomes a decoy substrate for IKK $\alpha$ where it competes with IRF7 to get phosphorylated by IKK $\alpha$. Nevertheless, the MeV $\mathrm{V}$ protein could not impair the IFN induction involving TBK1 and the related IKKe.

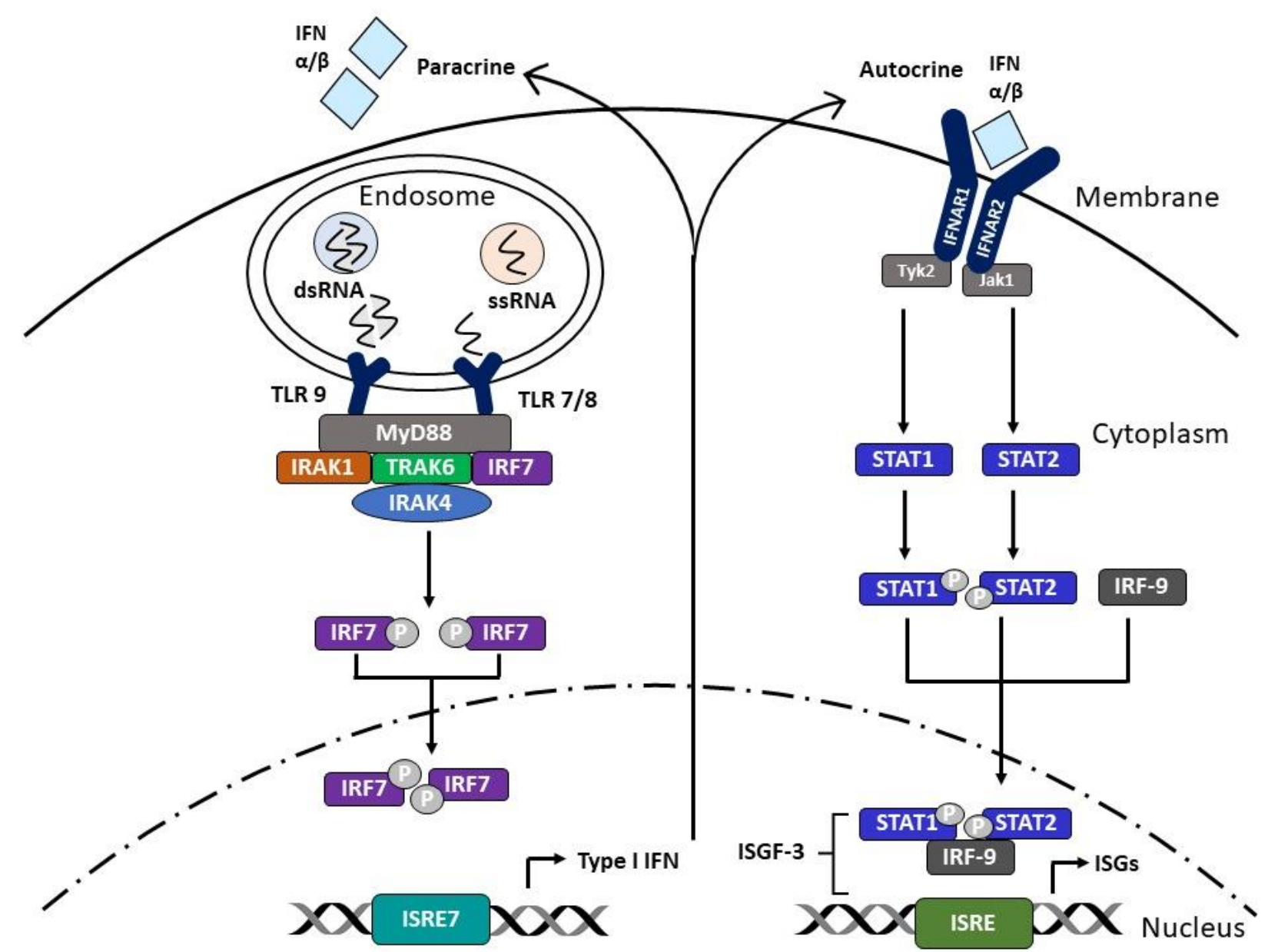

Figure 4. Type I IFN activation pathway. Paramyxoviruses are RNA viruses that enter the host cytoplasm through endocytosis. The Toll-like receptors (TLR) will interact with the pathogen-associated molecular patterns (PAMPs) which are the genetic material of viruses followed by activating the transcription factors interferon regulatory factor (IRF) to translocate into the nucleus and stimulate type I IFN transcription. 


\subsubsection{Nipah virus (NiV) and Hendra virus $(\mathrm{HeV})$ from genus Henipavirus}

The $\mathrm{V}$ protein for $\mathrm{NiV}$ and $\mathrm{HeV}$ in Henipavirus is known for the largest $\mathrm{V}$ protein across Paramyxoviridae where they share high similarities of amino acids sequence (Rodriguez and Horvath, 2004). They antagonise the host IFN system by binding the $\mathrm{V}$ proteins to both STAT1 and STAT2 proteins, to form a large trimeric complex (Rodriguez et al., 2002; 2003). The V protein has to bind to STAT1 proteins prior to interacting with STAT2 proteins (Rodriguez et al., 2004; Basler, 2012). This complex will be sequestrated in the cytoplasm, preventing the STAT proteins from translocating into the nucleus. The peptide sequence on $\mathrm{V}$ proteins known as CRM1dependent nuclear export signal (NES) allows the $\mathrm{V}$ protein to move into the nucleus and bind to the STAT proteins and translocate them out from the nucleus, resulting in retention of STAT proteins in the cytoplasm (Rodriguez et al., 2004; Rodriguez and Horvath, 2004). Recently, the N protein of $\mathrm{NiV}$ is also found to inhibit IFN signalling by preventing the STAT complex formation. As a result, translocation of activated STAT proteins from the cytoplasm to the nucleus is prohibited (Sugai et al., 2017). In addition, the $\mathrm{V}$ proteins inhibit the tyrosine phosphorylation of STATs proteins, but like that of the $\mathrm{MeV}$, the STAT proteins are not degraded. As a result, the IFN signalling is inhibited (Rodriguez et al., 2002). While the IFN antagonistic activity of other paramyxoviruses is correlated with cysteine rich $\mathrm{C}$ terminal of $\mathrm{V}$ protein, Park et al. (2003b) revealed that the IFN antagonistic property of Nipah virus is contributed by the $\mathrm{N}$ terminal of the $\mathrm{V}$ protein. The glutamic acid at residue 125 of NiV V protein seems to be contributing to IFN antagonism as well (Hagmaier et al., 2006). As compared to V protein, $\mathrm{W}$ protein are more effective at blocking activation of the ISG54 promoter, a promoter that can be activated by IRF-3 or IFN-induced transcription factor ISGF3 through the TLR3 signalling pathway (Shaw et al., 2005). According to Yoneda et al. (2010), Both the $\mathrm{V}$ and $\mathrm{C}$ proteins of Nipah virus are responsible for the virulence in vivo while the $\mathrm{W}$ protein does not. Besides, the $\mathrm{C}$ termini of the $\mathrm{V}$ protein for these two viruses were found to interact with the helicase domain of MDA-5 as well to suppress the IFN- $\beta$ transcription (Andrejeva et al., 2004; Childs et al., 2007). The ability of NiV to suppress RIG-I and MDA5-dependent interferon signalling is defined by the stabilisation of a regulator namely UBX domain-containing protein 1 (UBXN1) by the $\mathrm{V}$ protein (Uchida et al., 2018).

In short, STAT proteins are essential components to facilitate IFN activity. This is because expression and activation of IFNinduced genes require phosphorylation of STAT1 and STAT2 by JAK family (Qiu et al., 2016). However, STAT proteins often become the common target for paramyxovirus $\mathrm{V}$ protein. Upon interacting with the $\mathrm{V}$ protein, STAT proteins lose their ability to transmit the downstream IFN signalling. As a result, transcription of IFN-stimulated genes will be greatly reduced. In short, an impaired IFN system will turn down the viral resistance in the host cells which lead to rapid and successful multiplication of virus (Hengel et al., 2005). The strategy of Paramyxoviridae to counteract with the component of IFN system is summarised in Figure 5.

\section{The antagonistic activities of $\mathrm{V}$ protein carboxyl terminal}

The $\mathrm{C}$ terminal of the paramyxovirus $\mathrm{V}$ protein is known to have contributed to the IFN antagonistic activity (Liston and Briedis, 1994; Paterson et al., 1995; Steward et al., 1995; Huang et al., 2003; Park et al., 2003a; Qiu et al., 2016). It has seven conserved cysteine residues that can interact and formed a unique zinc finger fold with an invariant histidine (Figure 6). The zinc finger consists of two loops with different length and bounded with two zinc atoms per protein chain (Paterson et al., 1995; Steward et al., 1995; Ramachandran and Horvath, 2010). The integrity of the $\mathrm{C}$ terminal of $\mathrm{V}$ protein is important for its biological activity and any mutation on the cysteine residue will result in protein and biological activity dysfunctionality ( $\mathrm{He}$ et al., 2002). 


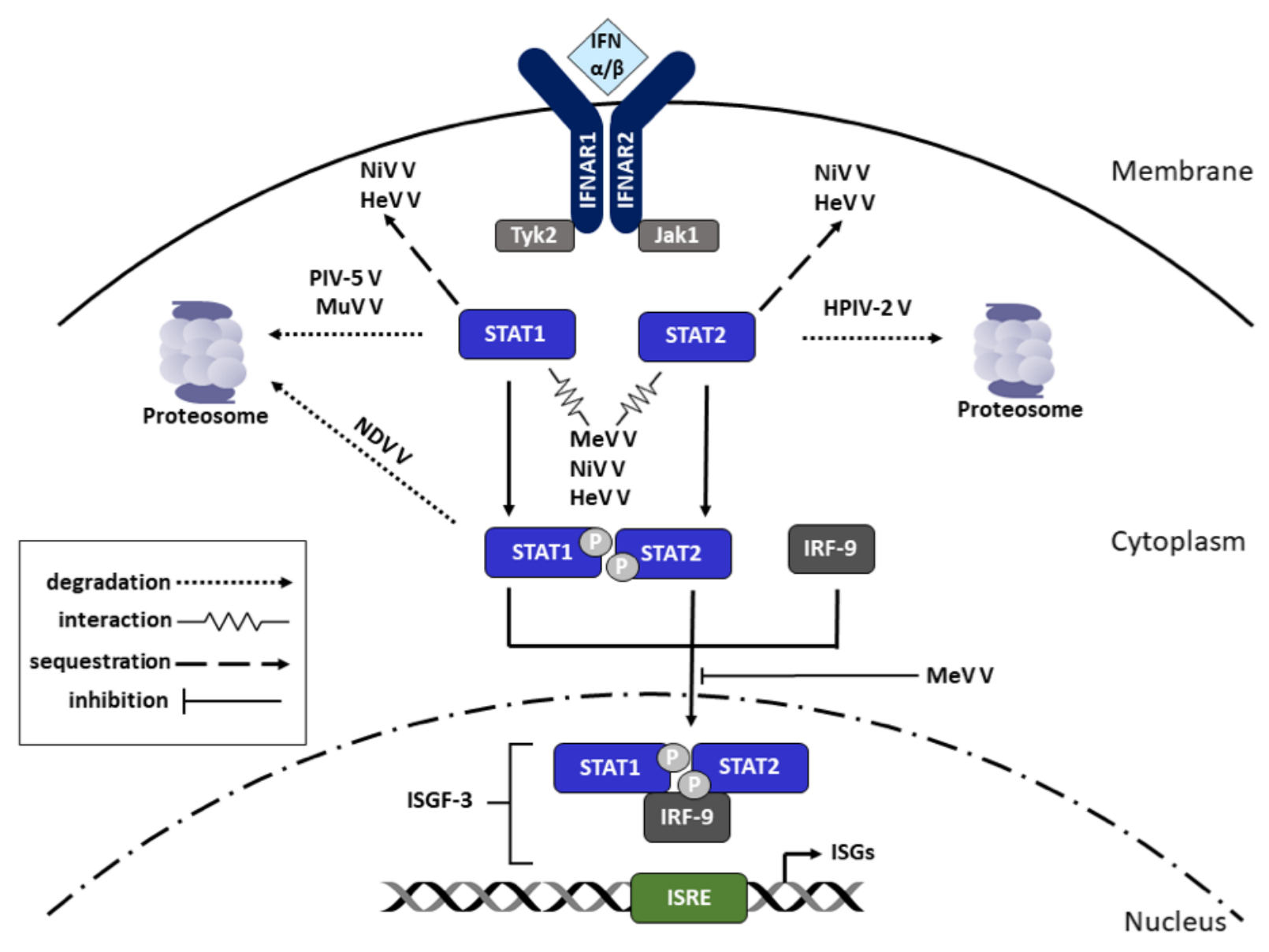

Figure 5. Inhibition of IFN-I signalling pathways by paramyxoviruses. The $\mathrm{V}$ protein of MuV and PIV5 directs STAT1 protein for proteasomal degradation whereas HPIV-2 V protein targets STAT2 protein degradation. Besides, NDV V protein selectively binds to phosphorylated STAT1 protein for ubiquitin mediated proteolytic degradation. MeV blocks the translocation of both STAT proteins into nucleus. Next, the $\mathrm{V}$ protein of $\mathrm{MeV}, \mathrm{NiV}$ and $\mathrm{HeV}$ inhibits the tyrosine phosphorylation of STATs protein. Meanwhile, $\mathrm{V}$ protein of $\mathrm{NiV}$ and $\mathrm{HeV}$ from Henipavirus sequestrates STAT1 and STAT2 proteins in cytoplasm by forming a large trimeric complex that is consist of both STATs proteins and V protein. Hence the displacement of STAT proteins into the nucleus is prohibited.

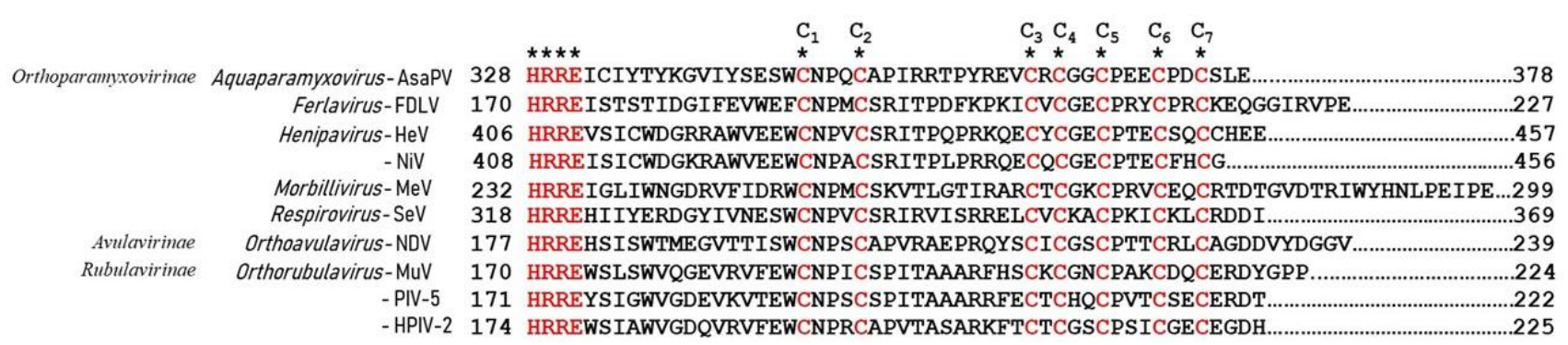

Figure 6. Amino acid sequence alignment in carboxyl terminal of $\mathrm{V}$ protein from different genus in the family Paramyxoviridae. The $\mathrm{N}$ terminal of the open reading frame is omitted and only the conserved region is shown with the amino acid residue number. The conserved seven cysteine residues are numbered and marked with asterisks above together with the conserved histidine that involved in zinc-binding. The example of virus is indicated next to the genus. AsaPV: Atlantic salmon paramyxovirus; FDLV: Fer-deLance virus; MuV: Mumps virus; PIV-5: Parainfluenza virus 5; HPIV-2; Human parainfluenza virus 2; NDV: Newcastle disease virus; SeV: Sendai virus; HeV: Hendra virus; NiV: Nipah virus; MeV: Measles virus (Modified from Audsley and Moseley, 2013). 
Mutation of the second cysteine of $\mathrm{V}$ protein by substitution to other amino acid will abolish the MDA interference by NiV and PIV- 5 whereas mutation of the first cysteine will still retain the $\mathrm{V}$ protein activity (Ramachandran and Horvath, 2010). In contrast, all the cysteine residues are required in order to maintain the interaction of $\mathrm{MDA}$ and the $\mathrm{V}$ protein of mumps virus and measles virus (Ramachandran and Horvath, 2010). In addition, the first conserved arginine residue present at the carboxyl terminal of the $\mathrm{V}$ protein is found to interact with MDA5 resulting in the interference of the MDA5 signal transduction in diverse paramyxoviruses such as PIV-5, MuV, MeV and NiV (Ramachandran and Horvath, 2010). The interaction between the $\mathrm{V}$ protein $\mathrm{C}$ terminal with RIG-I and TRIM25 is conserved in different genera within the Paramyxoviridae such as $\mathrm{NiV}, \mathrm{SeV}, \mathrm{MeV}$ and PIV5 to inhibit downstream RIG-I signalling (Sánchez-Aparicio et al., 2018).

Besides, substitution of cysteine with alanine at position 189, 207 and 214 in mumps virus causes the reduction of proteosome-mediated degradation of STAT1 (Kubota et al., 2002; Yokosawa et al., 2002). Furthermore, paramyxovirus such as MuV, HPIV-2, SV5 and $\mathrm{MeV}$ requires a $\mathrm{V}$ protein with intact $\mathrm{C}$ terminal in order to interact with DDB1. Any substitution of cysteine residues to another amino acid will disrupt this interaction (Lin et al., 1998).

In the case for NDV, the $\mathrm{C}$ terminal of the $\mathrm{V}$ protein is responsible for the interaction with CacyBP/SIP in order to prevent apoptosis (Chu et al., 2018). In 2010, Alamares et al. showed that there are four amino acids differences at the $\mathrm{C}$ terminal of $\mathrm{V}$ protein between lentogenic and mesogenic NDV strain where each residue has an effect on IFN antagonism. The virulence patterns of the $\mathrm{V}$ protein among the different NDV pathotypes was further investigated by Wang et al. (2019). Their studies revealed that the V protein from different NDV pathotypes will exhibit different levels of interferon antagonistic activity. For example, the $\mathrm{V}$ protein of velogenic NDV showed the most reduction in IFN- $\beta$ expression in NDV infected cells. Although NDV with same pathotypes share higher homology in amino acid sequence, the exact function of individual amino acids towards the interferon antagonism can only be known through the construction of recombinant NDV with specific $\mathrm{V}$ protein mutation (Wang et al., 2019).

In a conclusion, the ability to antagonise the host IFN system is important for viral pathogenesis. Further studies are required to determine the interaction between host proteins and the $\mathrm{V}$ proteins particularly in regulating the paramyxovirus replication (Chu et al., 2018). Finally, it is hoped that this review is able to convey a true understanding of the role of $\mathrm{V}$ protein as a virulence factor among paramyxovirus. Further analysis of viral anti-IFN strategies together with the mode of action of multiple virulence factors is definitely required not only from the perspective of in vitro, but the behaviour in natural infection as well.

\section{ACKNOWLEDGEMENTS}

This project is supported by the Universiti Putra Malaysia Putra Grant (GP/2018/9600700) and Newton Ungku Omar Fund (MR/P012795/1).

\section{REFERENCES}

Alamares, J. G., Elankumaran, S., Samal, S. K., \& Iorio, R. M. 2010. The interferon antagonistic activities of the $\mathrm{V}$ proteins from two strains of Newcastle disease virus correlate with their known virulence properties. Virus Research 147(1): 153-157.

Amarasinghe, G. K., Ayllón, M. A., Bào , Y., Basler, C. F., Bavari, S., Blasdell, K. R., Briese, T., Brown, P. A., Bukreyev, A., Balkema-Buschmann, A., Buchholz, U. J., Chabi-Jesus, C., Chandran, K., Chiapponi, C., Crozier, I., de Swart, R. L., Dietzgen, R. G., Dolnik, O., Drexler, J. F., Dürrwald, R., Dundon, W. G., Duprex , W. P., Dye, J. M., Easton, A. J., Fooks, A. R., Formenty, P. B. H., Fouchier, R. A. M., Freitas-Astúa, J., Griffiths, A., Hewson, R., Horie, M., Hyndman, T. H., Jiāng, D., Kitajima, E. W., Kobinger, G. P., Kondō, H., Kurath, G., Kuzmin, I. V., Lamb, R. A., Lavazza, A., Lee, B., Lelli, D., Leroy, E. M., Lř, J., Maes, P., Marzano, S. L., Moreno, A., Mühlberger, E., Netesov, S. V., Nowotny, N., Nylund, A., Økland, A. L., Palacios, G., Pályi, B., Pawęska, J. T., Payne, S. L., Prosperi, A., Ramos-González, P. L., Rima, B. K., Rota, P., Rubbenstroth, D., Shī, M., Simmonds, P., Smither, S. J., Sozzi, E., Spann, K., Stenglein, M.D., Stone, D.M., Takada, A., Tesh, R. B., Tomonaga, K., Tordo, N., Towner, J. S., van den Hoogen, B., Vasilakis, N., Wahl, V., Walker, P. J., Wang, L., Whitfield, A. E., Williams, J. V., Zerbini, F. M., Zhāng, T., Zhāng, Y., \& Kuhn, J. H. 2019. Taxonomy of the order Mononegavirales: update 2019. Archives of Virology 164(7): 1967-1980.

Andrejeva, J., Childs, K. S., Young, D. F., Carlos, T. S., Stock, N., Goodbourn, S., \& Randall, R. E. 2004. The V proteins of 
paramyxoviruses bind the IFN-inducible RNA helicase, mda-5, and inhibit its activation of the IFN- $\beta$ promoter. Proceedings of the National Academy of Sciences of the United States of America 101(49): 17264-17269.

Audsley, M. D. \& Moseley, G. W. 2013. Paramyxovirus evasion of innate immunity: Diverse strategies for common targets. World Journal of Virology 2(2): 57-70.

Basler, C. F. 2012. Nipah and Hendra Virus interactions with the innate immune system. Current Topics in Microbiology and Immunology 359: 123-152.

Caignard, G., Guerbois, M., Labernardiere, J. L., Jacob, Y., Jones, L. M., Wild, F., Tangy, F., \& Vidalain, P. O. 2007. Measles virus $\mathrm{V}$ protein blocks Jak1-mediated phosphorylation of STAT1 to escape IFN-alpha/beta signaling. Virology 368(2): 351-362.

Caignard, G., Bourai, M., Jacob, Y., Tangy, F., \& Vidalain, P. O. 2009. Inhibition of IFN- alpha/beta signaling by two discrete peptides within measles virus $\mathrm{V}$ protein that specifically bind STAT1 and STAT2. Virology 383(1): 112120.

Calain, P. \& Roux, L. 1993. The rule of six, a basic feature for efficient replication of Sendai virus defective interfering RNA. Journal of Virology 67(8): 4822-4830.

Chambers, P., Millar, N. S., Platt, S. G., \& Emmerson, P. T. 1986. Nucleotide sequence of the gene encoding the matrix protein of Newcastle disease virus. Nucleic Acids Research 14(22): 9051-9061.

Chatziandreou, N., Stock, N., Young, D., Andrejeva, J., Hagmaier, K., McGeoch, D. J., \& Randall, R. E. 2004. Relationships and host range of human, canine, simian and porcine isolates of simian virus 5 (parainfluenza virus 5). Journal of General Virology 85: 3007-3016.

Childs, K., Stock, N., Ross, C., Andrejeva, J., Hilton, L., Skinner, M., Randall, R., \& Goodbourn, S. 2007. Mda-5, but not RIG-I, is a common target for paramyxovirus $\mathrm{V}$ proteins. Virology 359(1): 190-200.

Choppin, P.W. \& Compans, R. W. 1975. Reproduction of paramyxoviruses, pp. 95-178. In H. Fraenkel-Conrat and R.R. Wagner. (ed.), Comprehensive Virology Vol. 4. New York: Plenum Press.

Chu, Z., Wang, C., Tang, Q., Shi, X., Gao, X., Ma, J., Lu, K., Han, Q., Jia, Y., Wang, X., Adam, F. E. A, Liu, H., Xiao, S., Wang, X., \& Yang, Z. 2018. Newcastle disease virus V Protein inhibits cell apoptosis and promotes viral replication by targeting CacyBP/SIP. Frontiers in Cellular and Infection Microbiology 8(304): 1-13.

Clemens, M. J. 1997. PKR: a protein kinase regulated by double stranded RNA. The International Journal of Biochemistry \& Cell Biology 29(7): 945-949.

Cox, R. M. \& Plemper, R. K. 2017. Structure and organization of paramyxovirus particles. Current Opinion in Virology 24: 105114.

Curran, J., De Melo, M., Moyer, S., \& Kolakofsky, D. 1991. Characterisation of the Sendai virus V protein with an antipeptide antiserum. Virology 184(1): 108-116.

De Leeuw, O. \& Peeters, B. 1999. Complete nucleotide sequence of Newcastle disease virus: evidence of the existence of a new genus within the subfamily Paramyxovirinae. Journal of General Virology 80(1): 131-136.

Devaux, P., von Messling, V., Songsungthong, W., Springfeld, C., \& Cattaneo, R. 2007. Tyrosine 110 in the measles virus phosphoprotein is required to block STAT1 phosphorylation. Virology 360(1): 72-83.

Devaux, P., Priniski, L., \& Cattaneo, R. 2013. The measles virus phosphoprotein interacts with the linker domain of STAT1. Virology 444(1-2): 250-256.

Didcock, L., Young, D. F., Goodbourn, S., \& Randall, R. E. 1999. The $\mathrm{V}$ protein of simian virus 5 inhibits interferon signalling by targeting STAT1 for proteasome-mediated degradation. Journal of Virology 73(12): 9928-9933.

Diebold, S. S., Kaisho, T., Hemmi, H., Akira, S, Reis, E., \& Sousa, C. 2004. Innate antiviral responses by means of TLR7mediated recognition of single-stranded RNA. Science 303(5663): 1529-1531.

Dortmans, J. C., Rottier, P. J., Koch, G., \& Peeters, B. P. 2010. The viral replication complex is associated with the virulence of Newcastle disease virus. Journal of Virology 84(19): 10113-10120.

Fearns, R. \& Plemper, R. K. 2017. Polymerases of paramyxoviruses and pneumoviruses. Virus Research 234: 87-102.

Floyd-Smith, G., Slattery, E., \& Lengyel, P. 1981. Interferon action: RNA cleavage pattern of a $\left(2^{\prime}-5^{\prime}\right)$ oligoadenylatedependent endonuclease. Science 212(4498): 1030-1032.

Ganar, K., Das, M., Sinha, S., \& Kumar, S. 2014. Newcastle disease virus: current status and our understanding. Virus Research 184: 71-81.

Gotoh, B., Komatsu, T., Takeuchi, K., \& Yokoo, J. 2001. Paramyxovirus accessory proteins as interferon antagonists. Microbiology and Immunology 45(12): 787-800.

Hagmaier, K., Stock, N., Goodbourn, S., Wang, L., \& Randall, R. (2006). A single amino acid substitution in the $\mathrm{V}$ protein of Nipah virus alters its ability to block interferon signalling in cells from different species. Journal of General Virology 87(12): 3649-3653.

Haller, O., Frese, M., \& Kochs, G. 1998. Mx proteins: mediators of innate resistance to RNA viruses. Revue scientifique et technique (International Office of Epizootics) 17(1): 220-230.

Harrison, M. S., Sakaguchi, T., \& Schmitt, A. P. 2010. Paramyxovirus assembly and budding: building particles that transmit infections. The International Journal of Biochemistry \& Cell Biology 42(9): 1416-1429.

He, B., Paterson, R. G., Stock, N., Durbin, J. E., Durbin, R. K., Goodbourn, S., Randall, R. E., and Lamb, R. A. 2002. Recovery of paramyxovirus simian virus 5 with a $\mathrm{V}$ protein lacking the conserved cysteine-rich domain: the multifunctional $\mathrm{V}$ protein blocks both interferon-beta induction and interferon signaling. Virology 303(1): 15-32.

Heil, F., Hemmi, H., Hochrein, H., Ampenberger, F., Akira, S., Lipford, G., Wagner, H., \& Bauer, S. 2004. Species-specific recognition of single-stranded RNA via Toll-like receptor 7 and 8. Science 303(5663): 1526-1529.

Hemmi, H., Takeuchi, O., Kawai, T., Kaisho, T., Sato, S., Sanjo, H., Matsumoto, M., Hoshino, K., Wagner, H., Takeda, K., \& Akira, S. 2000. A Toll-like receptor recognizes bacterial DNA. Nature 408(6813): 740-745.

Hengel, H., Koszinowski, U. H., \& Conzelmann, K. 2005. Viruses know it all: new insights into IFN networks. TRENDS in Immunology 26(7): 396-401.

Honda, K., Yanai, H., Mizutani, T., Negishi, H., Shimada, N., Suzuki, N., Ohba, Y., Takaoka, A., Yeh, W.C., \& Taniguchi, T. 2004. Role of a transductional- transcriptional processor complex involving MyD88 and IRF- 7 in Toll-like receptor signaling. Proceedings of the National Academy of Sciences of the United States of America 101(43): 15416-15421.

Hoshino, K., Sugiyama, T., Matsumoto, M., Tanaka, T., Saito, M., Hemmi, H., Ohara, O., Akira, S., and Kaisho, T. 2006. IkappaB kinase-alpha is critical for interferon-alpha production induced by Toll-like receptors 7 and 9 . Nature 440(7086): 949-953.

Huang, Z., Krishnamurthy, S., Panda, A., \& Samal, S. K. 2003. Newcastle disease virus $\mathrm{V}$ protein is associated with viral pathogenesis and functions as an alpha interferon antagonist. Journal of Virology 77(16): 8676-8685.

Jacobs, B. L. \& Langland, J. O. 1996. When two strands are better than one: the mediators and modulators of the cellular 
responses to double stranded RNA. Virology 219(2): 339349.

Kawai, T., Sato, S., Ishii, K.J., Coban, C., Hemmi, H., Yamamoto, M., Terai, K., Matsuda, M., Inoue, J., Uematsu, S., Takeuchi, O., \& Akira, S. 2004. Interferon- $\alpha$ induction through Tolllike receptors involves a direct interaction of IRF7 with MyD88 and TRAF6. Nature Immunology 5(10): 1061-1068.

Kubota T, Yokosawa N, Yokota S, \& Fujii N. 2002. Association of mumps virus $\mathrm{V}$ protein with RACK1 results in dissociation of STAT-1 from the alpha interferon receptor complex. Journal of Virology 76(24): 12676-12682.

Kubota, T., Yokosawa, N., Yokota, S., Fujii, N., Tashiro, M., \& Kato, A. 2005. Mumps virus V protein antagonizes interferon without the complete degradation of STAT1. Journal of Virology 79(7): 4451-4459.

Lin, G. Y., Paterson R. G., Richardson, C. D., \& Lamb, R. A. 1998. The $\mathrm{V}$ protein of the paramyxovirus SV5 interacts with damage-specific DNA binding protein. Virology 249(1): 189200.

Liu, Y. J. 2005. IPC: Professional Type 1 interferon-producing cells and plasmacytoid dendritic cell precursors. Annual Review of Immunology 23: 275-306.

Liston, P. \& Briedis, D. J. 1994. Measles virus V protein binds zinc. Virology 198(1): 399-404.

Lund, J.M., Alexopoulou, L., Sato, A., Karow, M., Adams, N. C., Gale, N. W., Iwasaki, A., \& Flavell, R. A. 2004. Recognition of single-stranded RNA viruses by Toll-like receptor 7 . Proceedings of the National Academy of Sciences of the United States of America 101(15): 5598-5603.

MacLachlan, N. J. \& Dubovi, E. J. 2017. Paramyxoviridae and pneumoviridae, pp. 327-356. In Fenner's Veterinary Virology (Fifth Edition). San Diego, Academic Press.

Mebatsion, T., Verstegen, S., Vaan, L. T., Romer-Oberdorfer, A., \& Schrier, C. C. 2001. A recombinant Newcastle disease virus with low-level $\mathrm{V}$ protein expression is immunogenic and lacks pathogenicity for chicken embryos. Journal of Virology 75(1): 420-428.

Nishio, M., Garcin, D., Simonet, V., \& Kolakofsky, D. 2002. The carboxyl segment of the mumps virus $V$ Protein associates with stat proteins in vitro via a tryptophan-rich motif. Virology 300(1): 92-99.

O’Brien, V. 1998. Viruses and apoptosis. Journal of General Virology 79(8): 1833-1845

Palosaari, H., Parisien, J. P., Rodriguez, J. J., Ulane, C. M., \& Horvath, C. M. 2003. STAT protein interference and suppression of cytokine signal transduction by measles virus $\mathrm{V}$ protein. Journal of Virology 77(13): 7635-7644.

Parisien, J. P., Lau, J. F., Rodriguez, J. J., Sullivan, B. M., Moscona, A., Parks, G. D., Lamb, R. A., \& Horvath, C. M. 2001. The $\mathrm{V}$ protein of human parainfluenza virus 2 antagonizes type I interferon responses by destabilizing signal transducer and activator of transcription 2. Virology 283(2): 230-239.

Park, M., Garcia-Sastre, A., Cros, J. F., Basler, C. F., \& Palese, P. 2003a. Newcastle disease virus V Protein is a determinant of host range restriction. Journal of Virology 77(17): 9522 9532.

Park, M., Shaw, M. L., Munoz-Jordan, J., Cros, J. F., Nakaya, T., Bouvier, N., Palese, P., Garcia-Sastre, A., \& Basler, C. F. 2003b. Newcastle disease virus (NDV)-based assay demonstrates interferon-antagonist activity for the NDV V Protein and the Nipah Virus V, W, and C Proteins. Journal of Virology 77(2): 1501-1511.

Parks, G. D. \& Alexander-Miller, M. A. 2013. Paramyxovirus activation and inhibition of innate immune responses. Journal of Molecular Biology 425(24): 4872-4892.

Paterson, R. G., Leser, G. P., Shaughnessy, M. A., \& Lamb, R. A. 1995. The paramyxovirus SV5 V protein binds two atoms of zinc and is a structural component of virions. Virology 208(1): 121-131.

Patterson, J. B., Thomas, D., Lewicki, H., Billeter, M. A., \& Oldstone, M.B.A. 2000. V and C proteins of measles virus function as virulence factors in vivo. Virology 267(1): 80-89.

Pfaller, C. K. \& Conzelmann, K-K. 2008. Measles virus V Protein is a decoy substrate for I $\chi \mathrm{B}$ kinase and prevents Toll-like receptor 7/9-mediated interferon induction. Journal of Virology 82(24): 12365-12373.

Perry, K., Perry, A. K., Chen, G., Zheng, D., Tang, H., \& Cheng, G. 2005. The host type I interferon response to viral and bacterial infections. Cell Research 15(6): 407-422.

Poole, E., He, B., Lamb, R. A., Randall, R. E., \& Goodbourn, S. (2002). The $\mathrm{V}$ proteins of simian virus 5 and other paramyxoviruses inhibit induction of interferon- $\beta$. Virology 303(1): 33-46.

Precious, B., Childs, K., Goodbourn, S., \& Randall, R. E. (2005). Simian virus $5 \mathrm{~V}$ protein acts as an adaptor, linking DDB1 to STAT2, to facilitate the ubiquitination of STAT1. Journal of Virology 79(21): 13434-13441.

Qiu, X., Fu, Q., Meng, C., Yu, S., Zhan, Y., Dong, L., Song, C., Sun, Y., Tan, L., Hu, S., Wang, X., Liu, X., Peng, D., Liu, X., \& Ding, C. 2016. Newcastle Disease Virus V Protein Targets Phosphorylated STAT1 to Block IFN-I Signaling. PLoS One 11(2): 1-23.

Ramachandran, A. \& Horvath, C. M. 2010. Dissociation of paramyxovirus interferon evasion activities: universal and virus-Specific Requirements for conserved V protein amino acids in MDA5 interference. Journal of Virology 84(21): 11152-11163.

Rodriguez, J. J., Parisien, J., \& Horvath, C. M. 2002. Nipah Virus $\mathrm{V}$ protein evades alpha and gamma interferons by preventing STAT 1 and 2 activation and nuclear accumulation. Journal of Virology 76(22): 11476-11483.

Rodriguez, J. J., Wang, L. F., \& Horvath, C. M. 2003. Hendra virus $\mathrm{V}$ Protein inhibits interferon signaling by Preventing STAT1 and STAT2 Nuclear Accumulation. Journal of Virology 77(21): 11842-11845.

Rodriguez, J. J. \& Horvath, C. M. 2004. Host evasion by emerging paramyxoviruses: Hendra virus and Nipah virus $\mathrm{V}$ proteins inhibit interferon signaling. Viral Immunology 17(2): 210-219.

Roulston, A., Marcellus, R. C., \& Branton P. E. 1999. Viruses and apoptosis. Annual Review of Microbiology 53: 577-628.

Sánchez-Aparicio, M. T., Feinman, L. J., García-Sastre, A., Shaw, \& M. L. 2018. Paramyxovirus V proteins interact with the RIG-I/TRIM25 regulatory complex and inhibit RIG-I signaling. Journal of Virology 92(6): 1-21.

Samuel, C. E. 2001. Antiviral actions of interferons. Clinical Microbiology Reviews 14(4): 778-809.

Shaw, M. L., Cardenas, W. B., Zamarin, D., Palese, P., \& Basler, C. F. 2005. Nuclear localization of the Nipah virus $W$ protein allows for inhibition of both virus- and toll-like receptor 3triggered signaling pathways. Journal of Virology 79(10): 60786088.

Steward, M., Vipond, I. B., Millar, N. S., \& Emmerson, P. T. 1993. RNA editing in Newcastle disease virus. Journal of General Virology 74(12): 2539-2547.

Steward, M., Samson, A. C., Errington, W., \& Emmerson, P. T. 1995. The Newcastle disease virus $\mathrm{V}$ protein binds zinc. Archives of Virology 140(7): 1321-1328.

Sugai, A., Sato, H., Takayama, I., Yoneda, M., \& Kai, C. 2017. Nipah and Hendra Virus nucleoproteins inhibit nuclear accumulation of signal transducer and activator of transcription 1 (STAT1) and STAT2 by interfering with their complex formation. Journal of Virology 91(21): 1-15.

Takeuchi, K., Kadota, S. I., Takeda, M., Miyajima, N., \& Nagata, K. 2003. Measles virus V protein blocks interferon (IFN)- 
$\alpha / \beta$ but not IFN $-\gamma$ signaling by inhibiting STAT1 and STAT2 phosphorylation. FEBS Letters 545(2-3): 177-182.

Takimoto, T. \& Portner, A. 2004. Molecular mechanism of paramyxovirus budding. Virus Research 106(2): 133-145.

Tanaka, N., Sato, M., Lamphier, M. S., Nozawa, H., Oda, E., Noguchi, S., Schreiber, R. D., Tsujimoto, Y., \& Taniguchi, T. 1998. Type I interferons are essential mediators of apoptotic death in virally death cells. Genes to Cells 3(1): 2937.

Topolskawo's, A. M., Chazin, W. J., \& Filipek, A. 2016. CacyBP/SIP - structure and variety of functions. Biocbimica et Biophysica Acta 1860(1 Pt A): 79-85.

Uchida, S., Horie, R., Sato, H., Kai, C., \& Yoneda, M. 2018. Possible role of the Nipah virus $\mathrm{V}$ protein in the regulation of the interferon beta induction by interacting with UBX domain-containing protein1. Scientific Reports 8(1): 1-13.

Wang, X., Dang, R., \& Yang, Z. 2019. The interferon antagonistic activities of the $\mathrm{V}$ proteins of NDV correlated with their virulence. Virus Genes 55(2): 233-237.

Xu, P., Luthra, P., Li, Z., Fuentes, S., D'Andrea, J.A., Wu, J., Rubin, S., Rota, P.A., \& He, B. 2012. The V Protein of Mumps Virus Plays a Critical Role in Pathogenesis. Journal of Virology 86(3): 1768-1776.

Yan, Y. \& Samal, S. K. 2008. Role of intergenic sequences in Newcastle disease virus RNA transcription and pathogenesis. Journal of Virology 82(3): 1323-1331.

Yokosawa, N., Kubota, T., \& Fujii, N. 1998. Poor induction of interferon-induced 2',5'-oligoadenylate synthetase (2-5 AS) in cells persistently infected with mumps virus is caused by decrease of STAT-1 alpha. Archives of Virology 143(10): 19851992.

Yokosawa, N., Yokota, S., Kubota, T., \& Fujii, N. 2002. C-terminal region of STAT-1alpha is not necessary for its ubiquitination and degradation caused by mumps virus $\mathrm{V}$ protein. Journal of Virology 76(24): 12683-12690.

Yoneda, M., Guillaume, V., Sato, H., Fujita, K., Georges-Courbot, M., Ikeda, F., Omi, M., Muto-Terao, Y., Wild, T. F., \& Kai, C. 2010. The nonstructural proteins of Nipah virus play a key role in pathogenicity in experimentally infected animals. PLoS One 5(9): 1-8.

Young, D. F., Chatziandreou, N., He., B., Didcock, L., Goodbourn, S., Lamb, R. A., \& Randall, R. E. 2001. Single amino acid substitution in the $\mathrm{V}$ protein of SV5 differentiates its ability to block IFN signaling in human and murine cells. Journal of Virology 75(7): 3363-3370.

Young, D. F., Didcock, L., Goodbourn, S., \& Randall, R. E. 2000. Paramyxoviridae use distinct virus-specific mechanisms to circumvent the interferon response. Virology 269(2): 383390.

Yusoff, K., Millar, N. S., Chambers, P., \& Emmerson, P. T. 1987. Nucleotide sequence analysis of the $\mathrm{L}$ gene of Newcastle disease virus: homologies with Sendai and vesicular stomatitis viruses. Nucleic Acids Research 15(10): 3961-3976.

Yusoff, K. \& Tan, W. S. 2001. Newcastle disease virus: macromolecules and opportunities. Avian Pathology 30(5): $439-455$. 